\title{
Key Strata Inducing Dynamic Disasters Based on Energy Condition: Criterion and Application
}

\author{
Chao Xu, ${ }^{1,2,3}$ Gang Yang, ${ }^{1}$ Haoshi Sun, ${ }^{1}$ Liangliang Qin, ${ }^{1}$ Kai Wang, ${ }^{1,2}$ Bo Ren, ${ }^{1,4}$ \\ and Zhijie Wen $\mathbb{1}^{2,3}$ \\ ${ }^{1}$ School of Emergency Management and Safety Engineering, China University of Mining and Technology (Beijing), Beijing, China \\ ${ }^{2}$ Beijing Key Laboratory for Precise Mining of Intergrown Energy and Resources, China University of Mining and \\ Technology (Beijing), Beijing, China \\ ${ }^{3}$ Key Laboratory of Mining Disaster Prevention and Control, Shandong University of Science and Technology, Qingdao, China \\ ${ }^{4}$ National Engineering Research Center for Coal Mine Gas Control, Huainan, China
}

Correspondence should be addressed to Zhijie Wen; 201527@cumtb.edu.cn

Received 15 December 2020; Revised 11 January 2021; Accepted 6 February 2021; Published 20 February 2021

Academic Editor: Chuangzhou Wu

Copyright $\odot 2021$ Chao Xu et al. This is an open access article distributed under the Creative Commons Attribution License, which permits unrestricted use, distribution, and reproduction in any medium, provided the original work is properly cited.

\begin{abstract}
The thick and hard rock strata (THRS) exist widely in coal measure strata, which control the movements of overlying rock strata in stopes. When THRS break, great energy is released, which could aggravate the risks of coal and gas outburst, rock burst, and other dynamic disasters. Therefore, the foundation and key of preventing dynamic disasters are to distinguish the THRS that could induce coal-rock dynamic disasters and to analyze the laws of rock stratum breaking and energy releasing. The paper proposed the theoretical calculation methods of the energy accumulation and attenuation of rock breaking which is greatly affected by the hanging length of rock strata and the spreading distance. One or more roof strata that play a leading role in inducing dynamic disasters of the underlying coal mass are defined as the key disaster-inducing strata (KDIS). The disaster-inducing coefficient (DIC) is defined and used as the criterion of KDIS. The greater the source energy, the shorter the spreading distance, and the smaller the attenuation coefficient are, the easier the roof strata are to become KDIS. The disaster-inducing ability of the main THRS was analyzed, and the igneous sill was judged as KDIS, taking the Yangliu Coal Mine as project background. The breaking laws of the igneous sill were obtained by the methods of UDEC numerical simulation and microseismic monitoring, which verified the criterion of KDIS.
\end{abstract}

\section{Introduction}

With the huge demand of economic development for energy and the gradual exhaustion of shallow coal resources, the depth of coal mining is increasing by $10-25 \mathrm{~m}$ per year in China $[1,2]$. The deep mining conditions are more complex with complicated geological structure, higher in situ stress, higher gas pressure, and lower permeability and strength of coal [3]. Therefore, the typical dynamic disasters such as rock burst and coal and gas outburst in deep mines are more and more frequent and serious, compared with those in shallow mines [4-8]. Thick and hard rock strata (THRS) exist widely in coal measure strata, which control the movements of overlying rock strata in stopes because of the great thickness, hardness, and integrity. In case of THRS failure and instability, huge elastic energy is released and transmitted to the stopes, which aggravates the risk of coal and rock dynamic disasters (Figure 1) $[9,10]$.

In recent years, a series of coal and rock dynamic disasters occurred in the environment of THRS and caused huge casualties and property losses. For example, a rock burst accident that killed six miners was triggered by the fracturing of a 550 m-thick conglomerate rock stratum in the Qianqiu coal mine on March 27, 2014 [11]. One person died in a coal and gas outburst accident under a $120 \mathrm{~m}$-thick igneous rock stratum in the Haizi coal mine on April 25, 2009 [12]. A water-gas ejection accident occurred with about $7800 \mathrm{~m}^{3}$ of water and $166400 \mathrm{~m}^{3}$ of gas which were ejected from the 


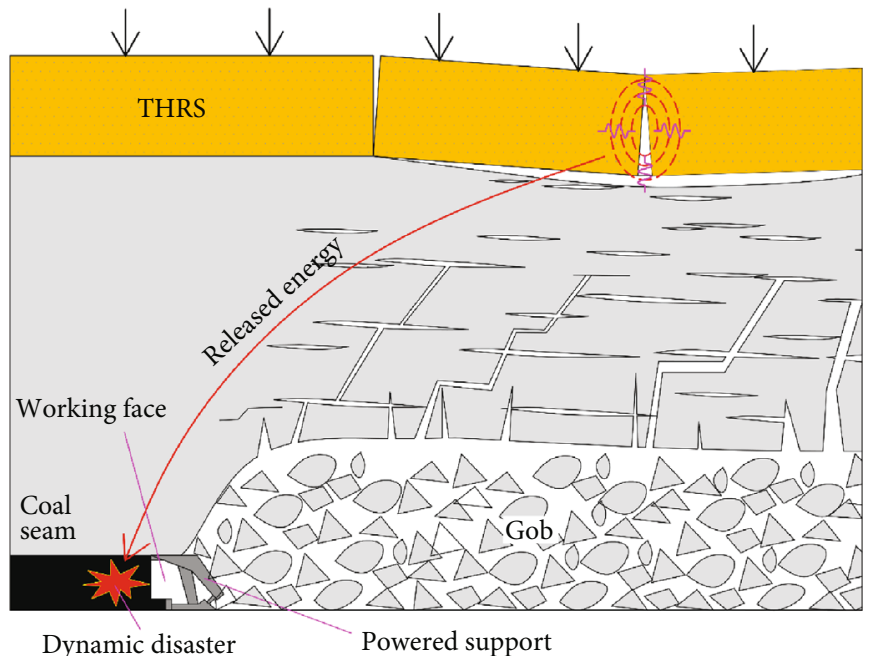

Figure 1: Schematic diagram of dynamic disasters induced by key strata.

bed-splitting space under the $43.6 \mathrm{~m}$-thick igneous rock stratum in the Yangliu coal mine on July 17, 2011 [13]. These examples highlight the need to investigate the effects of the THRS failure on the coal-rock dynamic disasters.

The strata are composed of coal and rock layers with uneven thickness and different strength. An increasing number of studies have focused on the recognizing and failure behaviors of THRS [14]. The key strata [15], which are usually thick-hard strata, play an important role in overlying movement and may influence the mining-induced strata behaviors in the working face using top-coal caving method [16]. Based on the key strata theory, an overburden caving model is proposed to predict the multilayered hard strata behavior [17]. The concept of key strata in immediate roof (KSIR) was put forward, and the dynamic effect and control mechanism of KSIR were studied [18]. Three kinds of structural model, which are affected by the relative position of key strata in the overburden, are found and defined [19]. A roof structural model for large mining-height stopes was established based on their overlying rock structure [20]. In situ measurements via vertical boreholes were performed to determine the key strata, and an innovative solution to fracture high-level hard strata by ground hydraulic fracturing was proposed [21, 22]. A physical modeling system was established to explore the fracture mechanism of the hard roof, and the characteristics of acoustic emission signals during the process of hard roof failure were also studied [23]. The key strata breakage could bring great effects on the stress redistribution and energy storage of mining coal seams. The cause and mechanism of localized stress concentration and rock failure behavior in rock interlayer after protective seam exploitation were explored by numerical simulation, mechanical model, and field investigation [24]. The microseismic effects of hard and thick igneous strata separation and fracturing and the corresponding evaluation index of fracturing intensity were analyzed [9]. For controlling the behavior of the high-located main key stratum (HMKS), a new technique is proposed to add grout between the separated beds during mining [25]. However, there are less literatures on how to distinguish the key strata inducing coalrock dynamic disasters.
In this paper, the laws of energy accumulation, spreading, and attenuation for the THRS instability was studied theoretically, the sensitivity of those influencing factors was analyzed, and then the concept and criterion of key disasterinducing strata (KDIS) were put forward. Afterwards, the KDIS in Yangliu Coal Mine, Huaibei Coalfield, China, was distinguished, in which results were verified by the numerical simulations and microseismic monitoring.

\section{Energy Spreading Laws of THRS Instability}

The elastic energy accumulated in THRS will be released rapidly and then spread and attenuated in the surrounding rock mass when THRS breaks. The residual energy could have a certain degree of impact action on the underlying coal under the state of ultimate stress, easily causing the irreversible damage and even the dynamic disasters.

2.1. Theoretical Analysis for Energy Spreading Laws. According to the stress state of roof strata, the total of the accumulated energy $E_{0}$ is composed of the bending elastic energy, the volumetric strain energy, and the kinetic energy generated by rock strata movement [26], which is expressed by

$$
E_{0}=\frac{q^{2} a_{0}^{5}}{576 E I}+\frac{(1-2 \mu)(1+2 k)^{2} q^{2}}{6 E}+\frac{1}{2} m\left(\frac{\mathrm{d} u}{\mathrm{~d} t}\right)^{2},
$$

where $q$ is the overburden load, $\mathrm{Pa} ; a_{0}$ is hanging length of roof strata, $\mathrm{m} ; E$ is the elasticity modulus, $\mathrm{Pa} ; \mu$ is Poisson's ratio; $k$ is the ratio of horizontal stress to vertical stress; $m$ is the mass of broken roof strata, $\mathrm{kg} ; u$ is the displacement of roof strata movement, $\mathrm{m}$; and $I$ is the inertia moment of roof strata, $\mathrm{m}^{4}$. For rectangular cross-section, $I=b h^{3} / 12$, in which $b$ and $h$ are the width and height of the rectangle, respectively.

It is known that the total of the accumulated energy before the failure of THRS is positively correlated with the hanging length, overburden load, and kinematic velocity of THRS. The larger the hanging length, overburden load, and kinematic velocity, the greater the accumulated energy. 


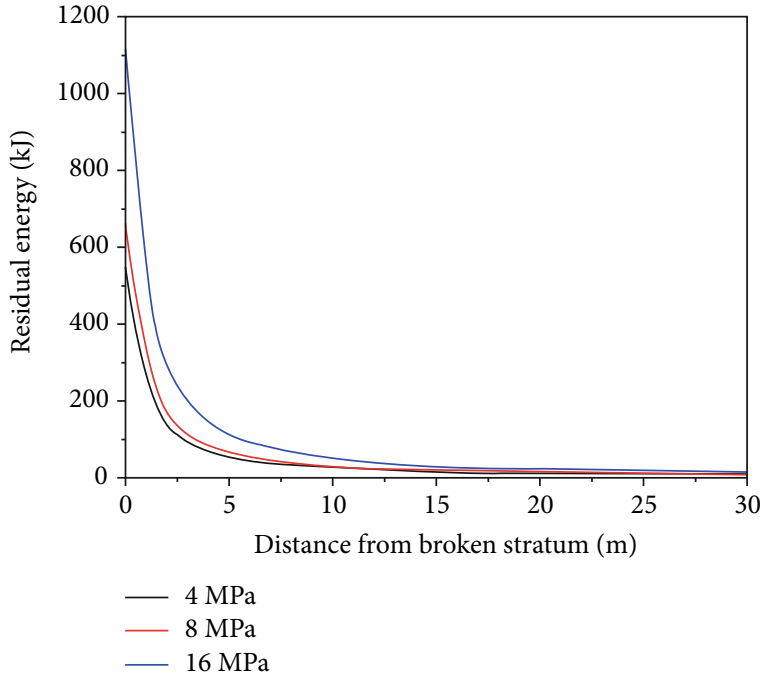

(a)

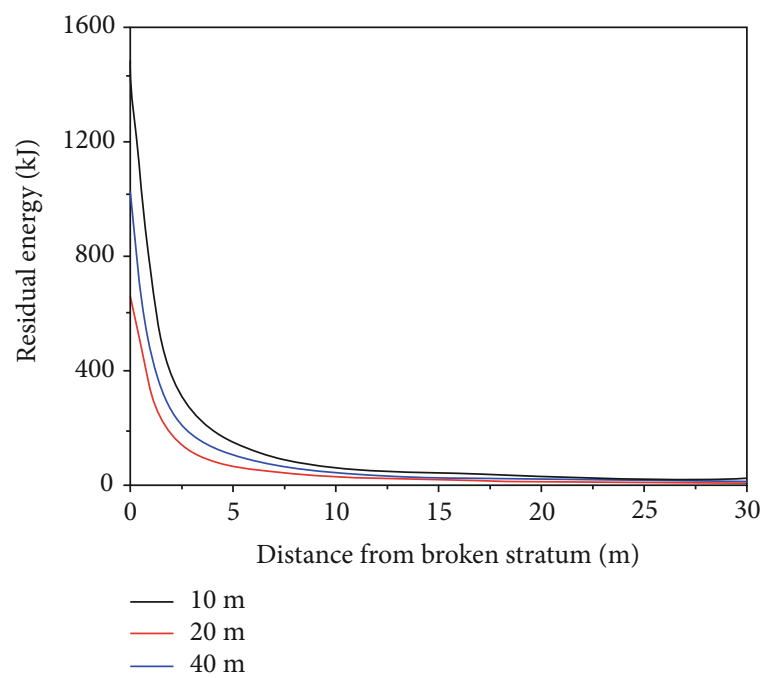

(c)

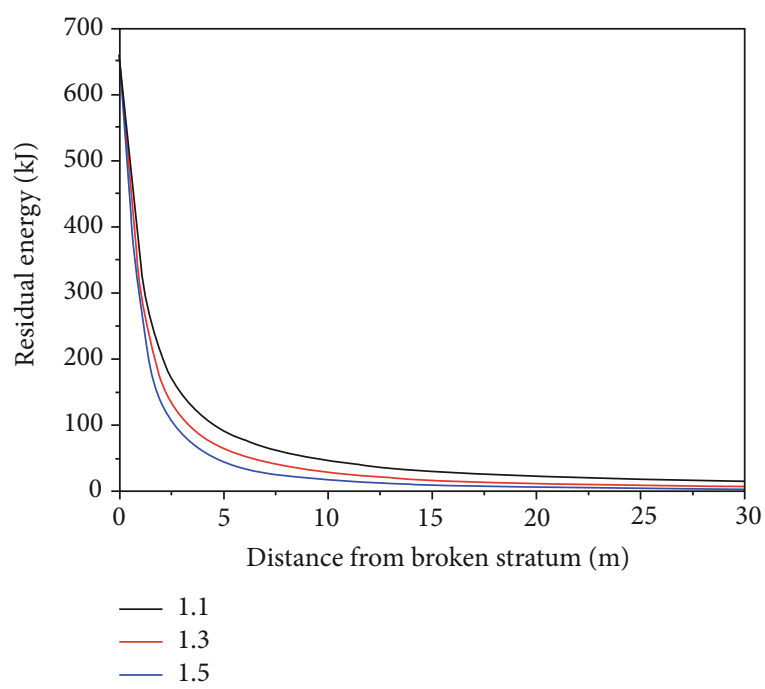

(e)

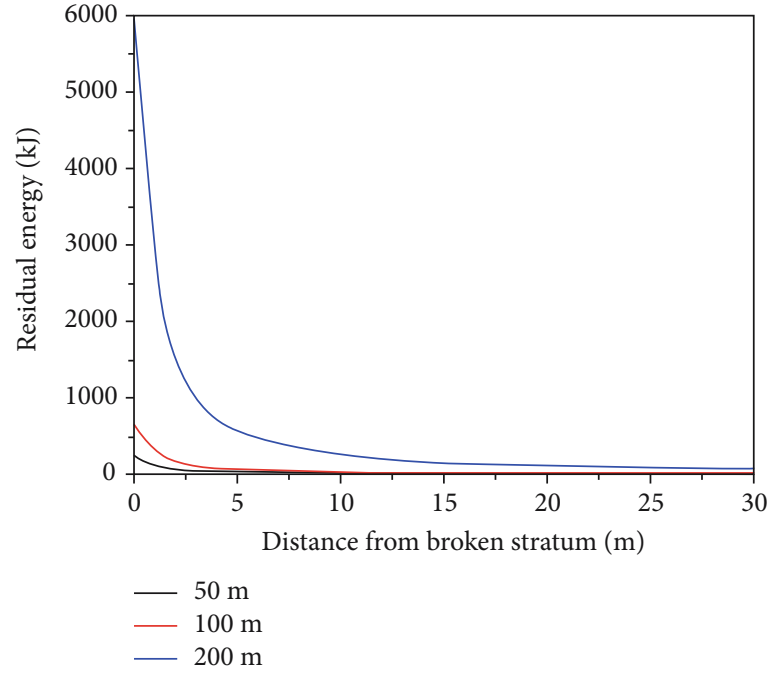

(b)

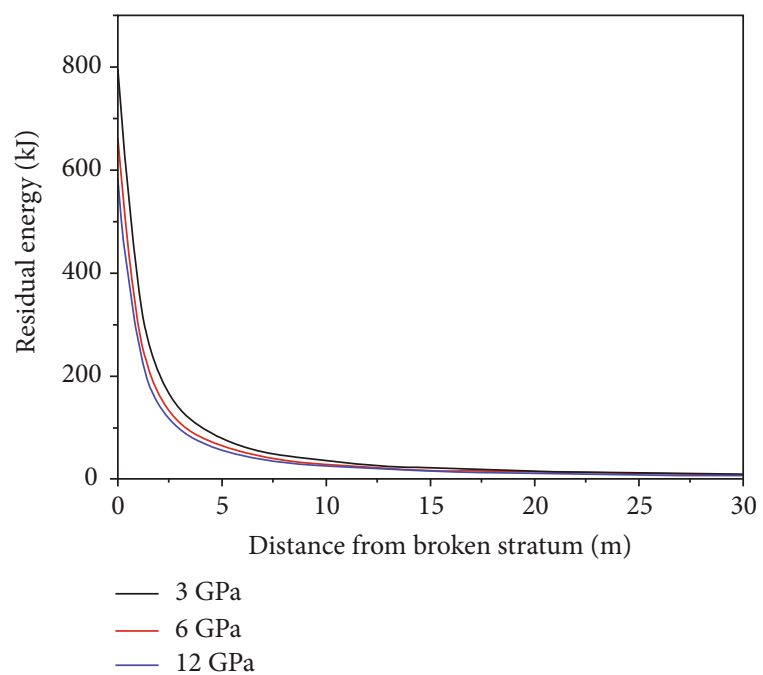

(d)

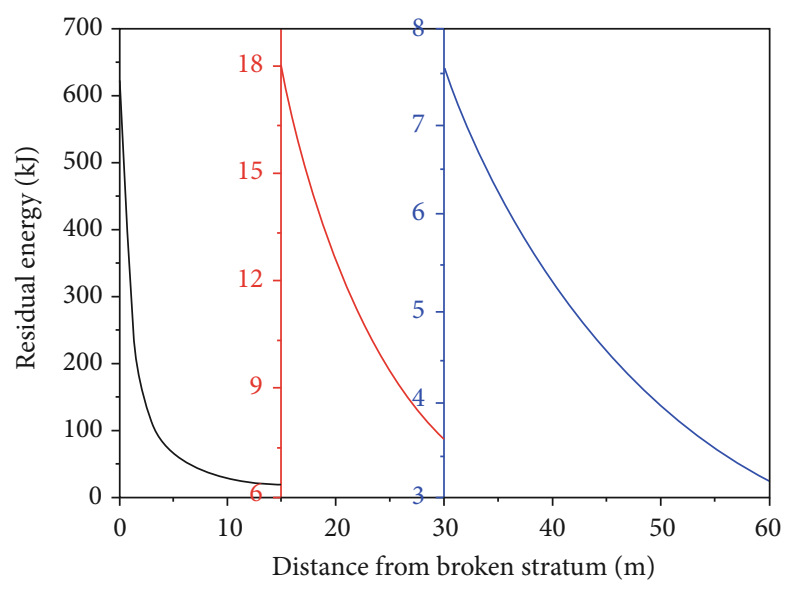

(f)

FIGURE 2: Sensitivity of influencing factors for energy spreading and attenuation. (a) Overburden load. (b) Hanging length of roof strata. (c) Thickness of roof strata. (d) Elasticity modulus of roof strata. (e) Mass of roof strata. (f) Energy attenuation coefficient. 


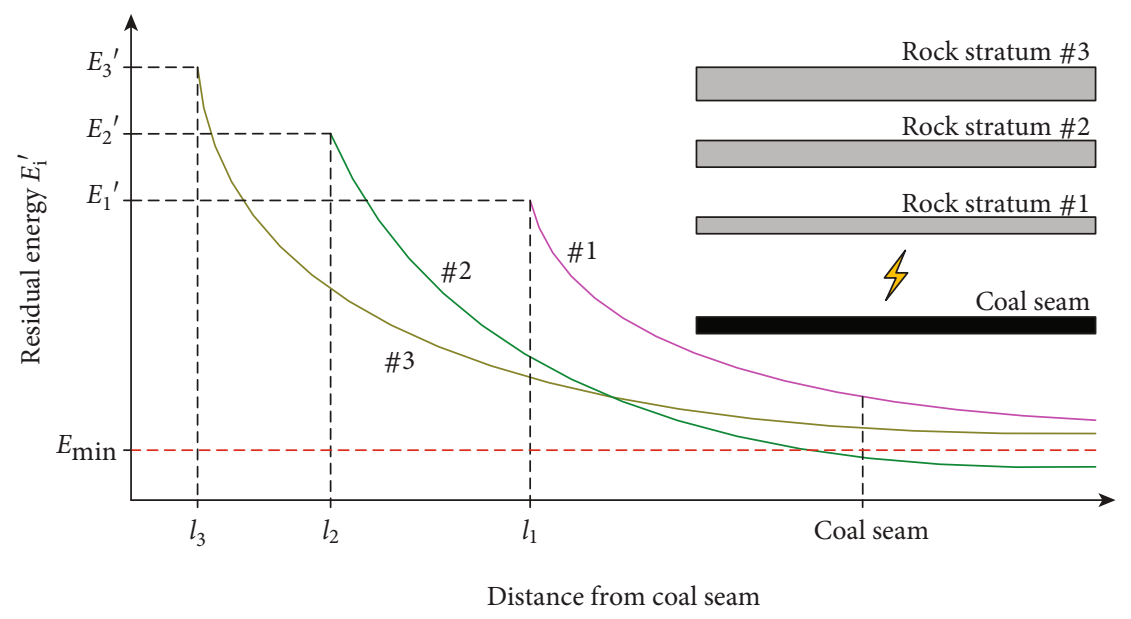

FIGURE 3: Energy attenuation laws for roof rock breakage against distance.

The energy will be released rapidly and then spread and attenuated in the surrounding rock mass when THRS breaks. However, only about $1 \% \sim 10 \%$ of the energy is spread in the form of seismic waves while most of the energy is converted to heat during collisions of THRS with other rocks [27]. The energy of seismic waves decreases gradually in the form of power with the increase of spreading distance due to the heterogeneity and damping effect of rock strata. From the perspective of safety protection, it could be assumed that $10 \%$ of the energy is converted into seismic waves, and then the residual energy after attenuation $E_{0}^{\prime}$ is

$$
E_{0}^{\prime}=0.1 E_{0} l^{-\lambda}
$$

where $l$ is the spreading distance, $m$, and $\lambda$ is the energy attenuation coefficient that is related to the properties of the medium.

The residual energy decreases with the increasing of the energy spreading distance and attenuation coefficient. Assuming that the seismic waves are spread in $m$ strata with the thickness of $h_{1}, h_{2}, h_{3}, \ldots, h_{m}$, in turn, the residual energy $E_{m}^{\prime}$ would be

$$
E_{m}^{\prime}=0.1 E_{0} \prod_{1}^{m} h_{i}^{-\lambda_{i}}
$$

It indicates that the THRS with the hanging length $a_{0}$ accumulates the energy $E_{0}$; when THRS breaks, the energy is spread in $m$ strata with the thickness of $h_{1}, h_{2}, h_{3}, \ldots, h_{m}$ in turn and attenuated to $E_{m}^{\prime}$.

2.2. Sensitivity of Influencing Factors for Energy Spreading. The energy accumulation and spread laws are related to many influencing factors, such as the overburden load, the hanging length, thickness, elasticity modulus and mass of roof strata, energy spreading distance, and attenuation coefficient based on the above formula. The sensitivity of influencing factors was obtained when they were assigned the different values ( 1 time, 2 times, and 4 times), assuming that the seismic waves were spread in the isotropous rock strata (Figure 2). When the load is increased by 2 times and 4 times, the initial seismic wave energy increases by 1.22 times and 2.08 times, respectively; however, when the hanging length is increased by 2 times and 4 times, the initial seismic wave energy increases by 2.55 times and 23.04 times, respectively. When the thickness and elasticity modulus of rock strata increase, the initial seismic wave energy decreases gradually, which is contrary to the common understanding. It is because that only the single influence of rock thickness or elasticity modulus on initial seismic wave energy is considered. In fact, the rock strata are more difficult to be broken and form larger hanging length when the thickness and elasticity modulus of rock strata increase and so the greater seismic wave energy will be released when the rock strata are broken [28]. The attenuation velocity of seismic wave energy increases with the increase of energy attenuation coefficient. If the energy attenuation coefficients are set as $1.1,1.3$, and 1.5 , the seismic wave energy will be attenuated to $1 / 14$, $1 / 22.6$, and $1 / 36.5$ of the initial values, respectively, when the seismic waves are spread $10 \mathrm{~m}$. The seismic wave energy is attenuated in the form of powers with the increasing of spreading distance. The seismic wave energy will be attenuated to $1 / 33.8,1 / 86.8$, and $1 / 209.4$ of the initial values, respectively, when the spreading distances increase by 2 times and 4 times from $15 \mathrm{~m}$. The comprehensive analysis shows that the spread of seismic wave energy is greatly affected by the hanging length of rock strata and the spreading distance.

\section{Concept and Criterion of KDIS}

3.1. Concept of KDIS. Although most of the released energy has been dissipated, the residual energy may still induce dynamic disasters when the seismic waves were spread to the mining coal seam. Therefore, one or more roof strata that play a leading role in inducing dynamic disasters of the underlying coal mass are defined as the key disasterinducing strata (KDIS). The residual energy not only depends on the size and mechanical properties of rock strata but also relates to the energy spreading distance and attenuation coefficient. The greater the source energy, the shorter 


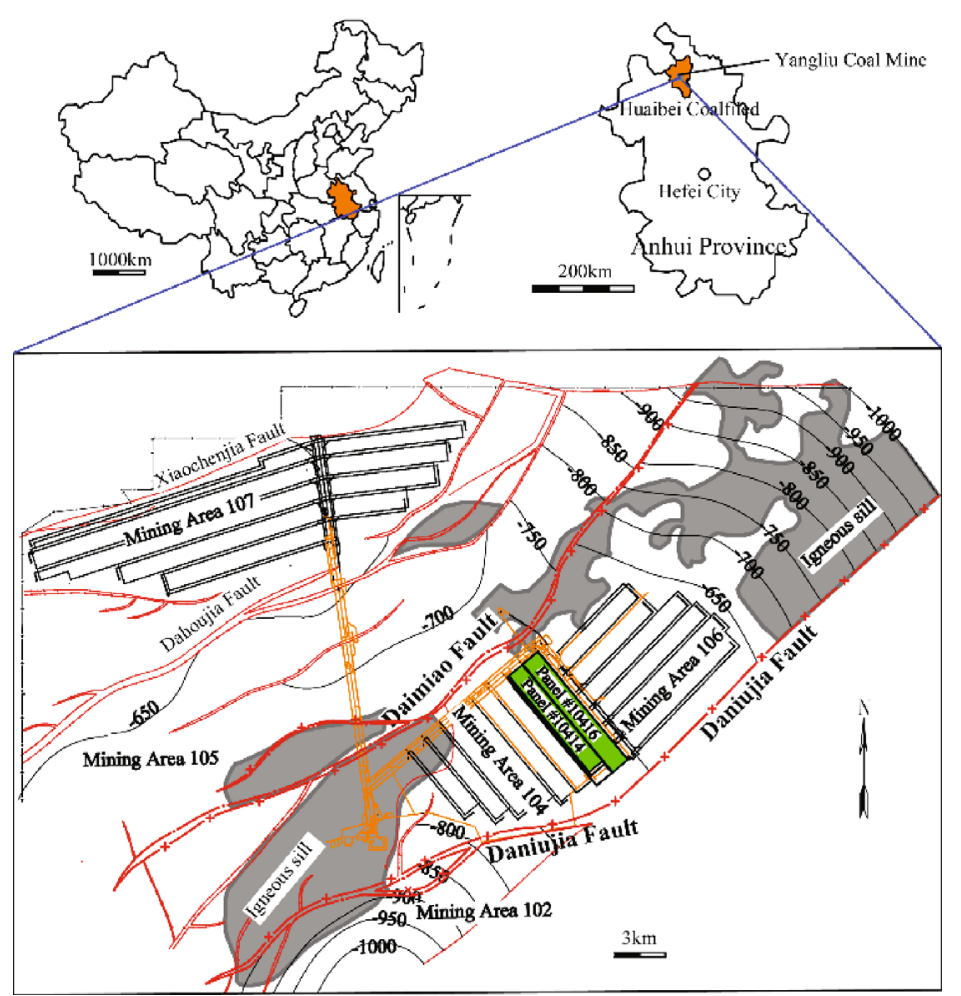

Contour

LP Fault

$\square$ Igneous sill

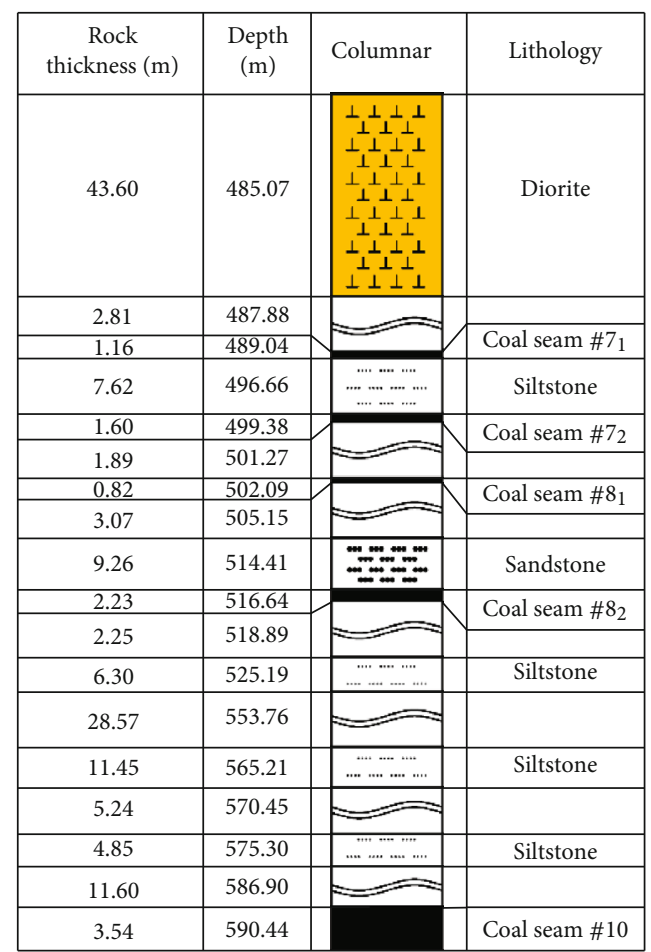

(b)

(a)

Figure 4: Project background of Yangliu Coal Mine.

the spreading distance, and the smaller the attenuation coefficient are, the stronger the disaster-inducing ability of the roof strata is, and the easier the roof strata are to become KDIS. However, the key stratum of ground control mainly depends on the size and mechanical properties of the rock stratum itself [15]. Thus, the key stratum of ground control is not exactly equal to KDIS.

Figure 3 provides a better understanding of KDIS. When the rock stratum \#1 that is close to the mining coal seam is broken, the residual energy may be larger than the minimum energy inducing dynamic disasters although the released energy is less. When the thicker rock stratum $\# 2$ is broken, more seismic wave energy is released but cannot induce dynamic disasters due to the relatively large distance from the mining coal seam. But for the thick rock stratum \#3 which is the key stratum of ground control, great seismic wave energy is released when broken, and the residual energy is so large that could induce dynamic disasters although it is far from the mining coal seam. Therefore, the rock strata \#1 and \#3 are the KDIS, and the key stratum of ground control may be the KDIS under certain conditions.

3.2. Criterion of KDIS. During the process of dynamic disaster occurring, the crushing work is needed for crack propagation, debris stripping, and new surface forming of coal mass; the kinetic energy is needed for throwing the broken coal into the excavation space; the friction dissipation energy is also needed for overcoming the inner friction during the broken coal peeling and throwing. Thus, the total energy consumption is composed of the crushing work, the kinetic energy, and the friction dissipation energy. If the accumulated energy of mining coal mass is larger than the total energy consumption, the dynamic disasters will occur.

They are assumed that there are $n$ overlying rock strata with the distances $l_{1}, l_{2}, l_{3}, \ldots, l_{n}$ from the mining coal seam, respectively, and that the seismic wave energy $E_{1}, E_{2}, E_{3}, \ldots, E_{n}$ will be released and attenuated with the average attenuation coefficient $\lambda_{0}$ when they are broken. The residual energy $E_{1}^{\prime}, E_{2}^{\prime}, E_{3}^{\prime}, \ldots, E_{n}^{\prime}$ when spreading to the mining coal seam is, respectively

$$
\left\{\begin{array}{l}
E_{1}^{\prime}=E_{1} l_{1}^{-\lambda_{0}} \\
E_{2}^{\prime}=E_{2} l_{2}^{-\lambda_{0}} \\
E_{3}^{\prime}=E_{3} l_{3}^{-\lambda_{0}} \\
\cdots \\
E_{n}^{\prime}=E_{n} l_{n}^{-\lambda_{0}} .
\end{array}\right.
$$

The ratio of the residual energy $E_{i}^{\prime}$ and the minimum energy inducing dynamic disasters $E_{\min }$ is defined as the disasterinducing coefficient (DIC) $\xi$, that is $\xi=E_{i}^{\prime} / E_{\min }$. Based on DIC, THRS are divided into three types: KDIS, the weak 
TABLE 1: Criterion results of KDIS in Yangliu Coal Mine.

\begin{tabular}{lcccc}
\hline No. & $\# 1$ & $\# 2$ & $\# 3$ & $\# 4$ \\
\hline Lithology & Sandstone & Siltstone & Sandstone & Igneous rock \\
Thickness (m) & 4.8 & 11.5 & 9.3 & 72 \\
Distance from coal seam \#10 (m) & 12 & 21 & 18.7 & 102 \\
Extreme hanging length (m) & 16.7 & 20.0 & 0.48 & 184.6 \\
Released energy (MJ) & 0.31 & 0.63 & 0.28 & 41.10 \\
Residual energy spreading to coal seam \#10 (kJ) & 1.55 & 0.162 & 0.028 & 1.62 \\
DIC & 0.155 & WDIS & NDIS \\
Criterion result & WDIS & KDIS \\
\hline
\end{tabular}

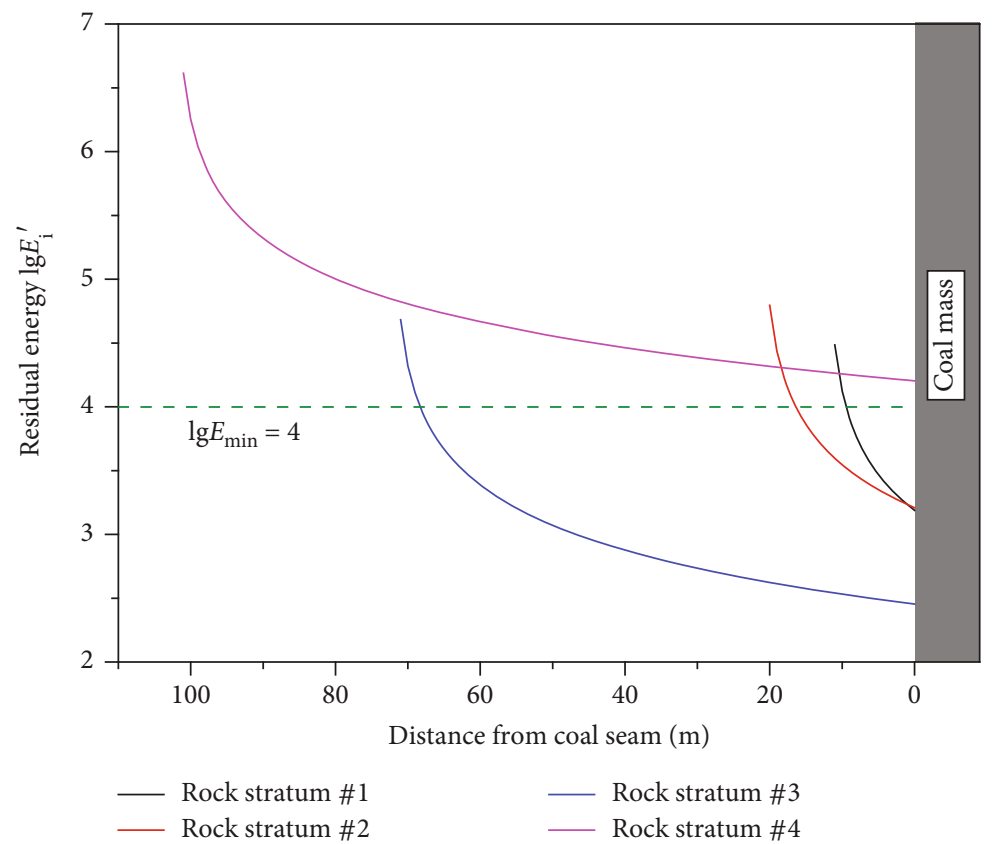

Figure 5: Energy attenuation laws of rock strata in Yangliu Coal Mine.

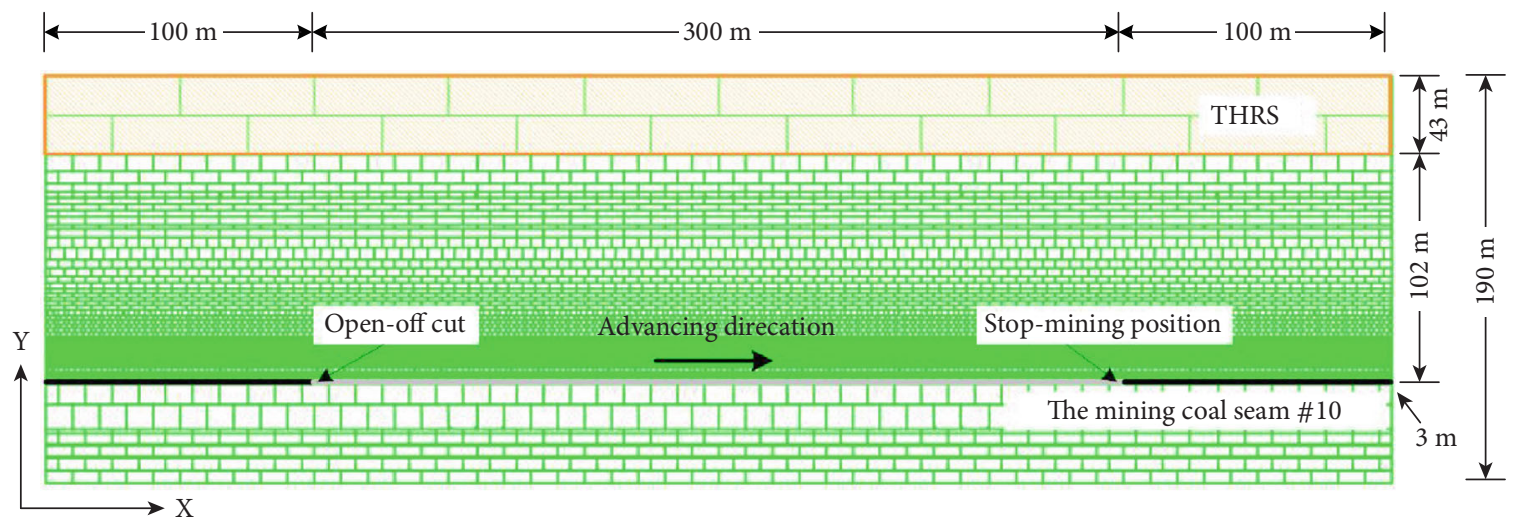

FIgURE 6: UDEC numerical model.

disaster-inducing stratum (WDIS), and the non-disasterinducing stratum (NDIS). If $\xi \geq 1$, the broken rock strata could induce dynamic disasters, which are distinguished to be KDIS; if $0.1 \leq \xi<1$, the broken rock strata may induce dynamic disasters considering in situ stress, mechanical properties of coal, and other factors, which are distinguished to be WDIS; if $\xi<0.1$, the broken rock strata could not induce dynamic disasters, which are distinguished to be NDIS. 


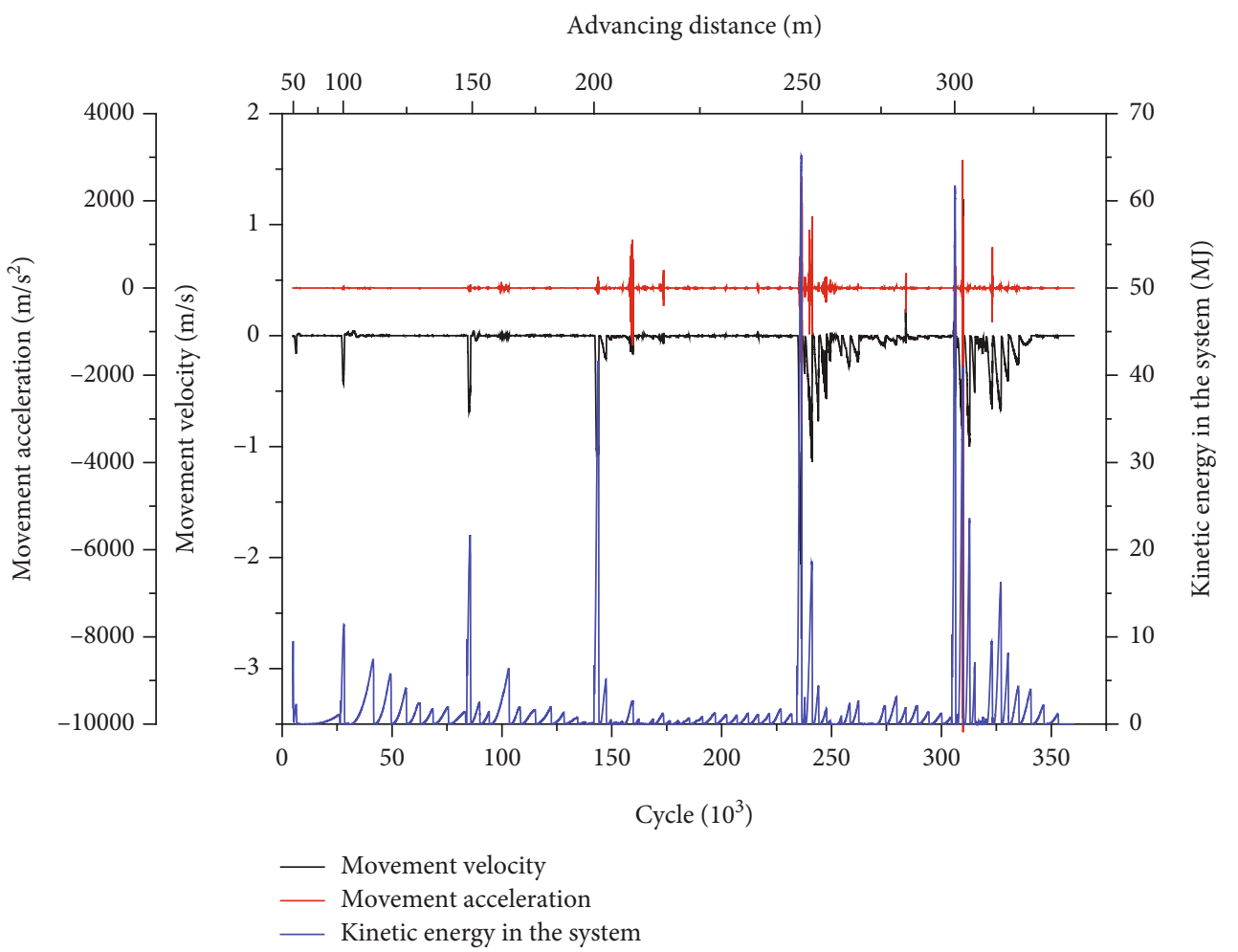

Figure 7: Movement laws of igneous sill.

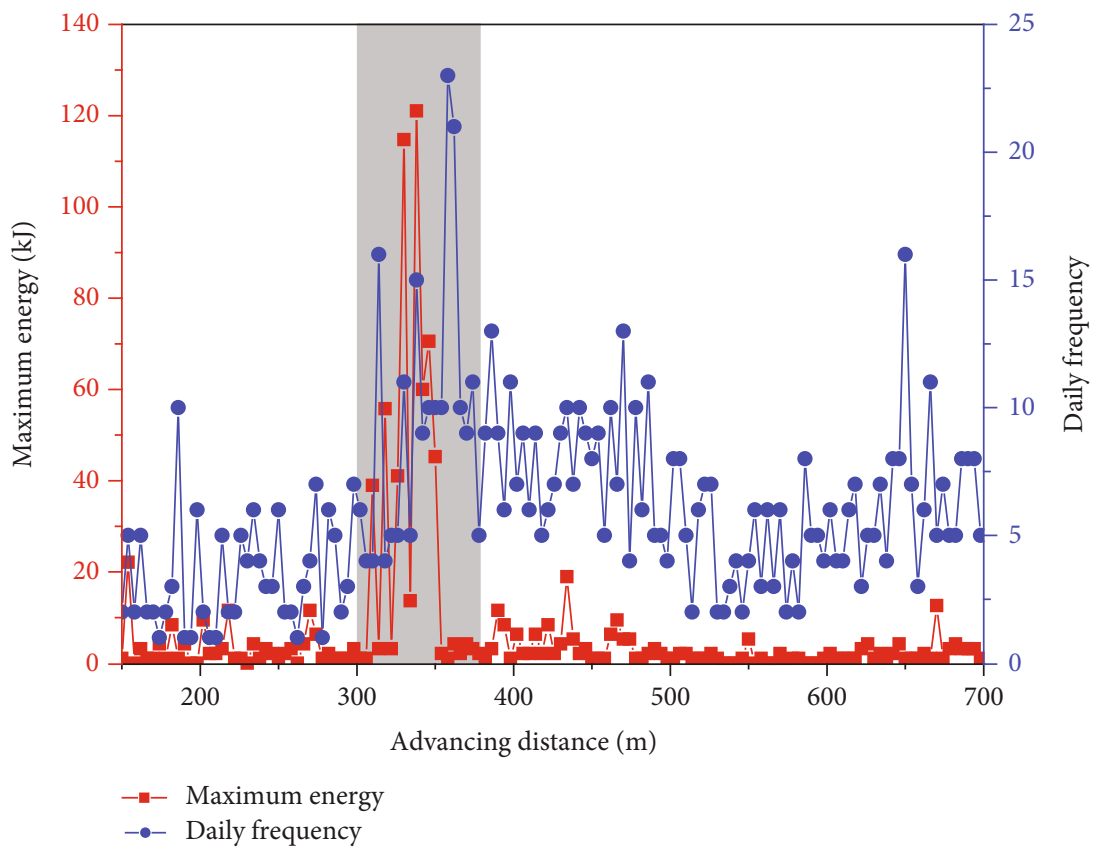

Figure 8: Daily frequency and maximum energy of the panel \#10416.

\section{Engineering Application}

4.1. Project Background. Yangliu Coal Mine, the coal and gas outburst mine, is located in the north Anhui province, China. The coal seam \#10 with the average thickness of $3.19 \mathrm{~m}$ is the main mining seam adopting the comprehensive mechanized mining method. The magmatic activities in Yangyan Coal Mine were quite intense, and almost all coal seams were affected by magmatic intrusion. The igneous sill, $43.6 \mathrm{~m}$ thick averagely and $102 \mathrm{~m}$ above the coal seam \#10, is the key stratum of ground control (Figure 4). The panel \#10414 and the adjacent panel \#10416 of the coal seam \#10 were mined in 
turn. According to the statistics, multiple dynamic disasters were induced by the movement and failure of the igneous sill during the two panels mining. The large amount of water and gas were ejected from the surface well when the panel \#10414 was advanced $527 \mathrm{~m} \mathrm{[13];} \mathrm{the} \mathrm{abnormal} \mathrm{pressure} \mathrm{on} \mathrm{working}$ face occurred when the panel \#10416 was advanced $320 \mathrm{~m}$ [28].

4.2. Criterion Results of KDIS. It can be preliminarily analyzed from the column chart of coal-bearing strata that the four thick rock strata, $12 \mathrm{~m}, 21 \mathrm{~m}, 72 \mathrm{~m}$, and $102 \mathrm{~m}$ above the coal seam \#10, respectively, may have the ability to induce dynamic disasters. The released energy of the four rock strata breaking and the residual energy spreading to the coal seam \#10 were calculated based on the above formula (Table 1 and Figure 5). Researches show that the minimum energy inducing dynamic disasters $E_{\text {min }}$ is $10^{4}$ orders of magnitude [29]. Assuming that the minimum energy inducing dynamic disasters in the coal seam \#10 of Yangliu Coal Mine is $10 \mathrm{~kJ}$ for security, the DIC of the four rock strata were 0.155 , $0.162,0.028$, and 1.598 , respectively. So the rock strata \#1 and \#2 were judged to be WDIS, the stratum \#3 to be NDIS, and the stratum \#4 to be KDIS. The breaking of the stratum \#4 could induce the dynamic disasters in coal seam \#10.

4.3. Result Validation. The methods of UDEC numerical simulation and microseismic monitoring were adopted for verifying the THRS failure and energy releasing laws.

4.3.1. UDEC Numerical Simulation. The numerical model is $190 \mathrm{~m}$ high from $50 \mathrm{~m}$ below the coal seam \#10 to the top of the igneous sill. The model size is $500 * 190 \mathrm{~m}$ while the panel size is $300 * 3 \mathrm{~m}$ and the coal pillars with $100 \mathrm{~m}$ width were set at each end (Figure 6). The Mohr-Coulomb criterion was selected, and the mechanical parameters of the coal and rock masses and joint surface were set as shown in the reference [26]. The bottom, left, and right boundaries of the model were set to obey the zero-displacement constraint, and the top boundary was loaded at $10 \mathrm{MPa}$. The excavation of the panel took place in six steps, each of which was $50 \mathrm{~m}$.

The movement velocity and acceleration of the igneous sill and the kinetic energy in the system were recorded by the orders yvel, yacc, and energy, respectively (Figure 7). The movement velocity and acceleration of the igneous sill at the central position $(250,155)$ increased gradually with the workface advancing. When the workface was advanced $250 \mathrm{~m}$, the movement velocity increased to the maximum of $-2.6 \mathrm{~m} / \mathrm{s}$, the acceleration increased to about $3000 \mathrm{~m} / \mathrm{s}^{2}$, and the kinetic energy extended to the maximum of $59.3 \mathrm{MJ}$, which were consistent with the previous calculated results. When the workface advanced $300 \mathrm{~m}$, the maximum of the movement velocity was $1.2 \mathrm{~m} / \mathrm{s}$ and the acceleration increased to $-9600 \mathrm{~m} / \mathrm{s}^{2}$ while the kinetic energy decreased to the $56.2 \mathrm{MJ}$ due to the collision and rebound between the igneous sill and the underlying rock strata. It was indicated that the igneous sill had been broken when the workface was advanced 250 300 m, and the released kinetic energy was much larger than that of the common rock strata. The igneous sill would force greater impact on the underlying

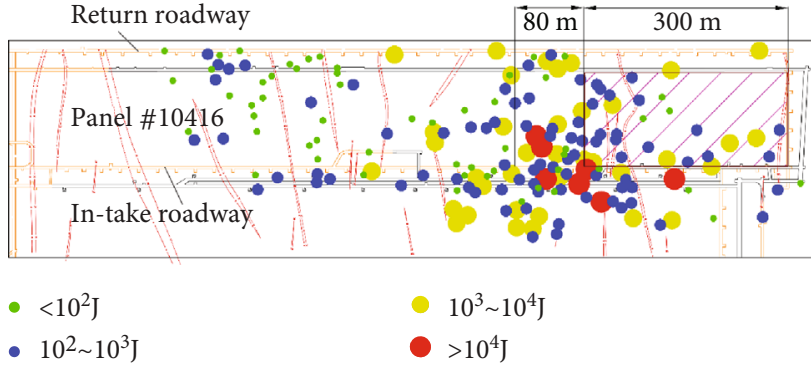

FIGURE 9: Microseismic event distribution.

coal seam and conformed to the characteristics of KDIS, which verified the above research results.

4.3.2. Microseismic Monitoring. The microseismic monitoring technology is a method to monitor the stability of engineering rock mass using the vibration waves emitted by the rock mass deformation and failure [30-32]. The SOS microseismic monitoring system was used to monitor the microseismic signals in real time in Yangliu Coal Mine. The daily frequency and maximum energy of seismic waves during the workface \#10416 advancing are shown in Figure 8. When the workface \#10416 was advanced $300 \sim 380 \mathrm{~m}$, the igneous sill was broken with square form [28], and thus, the daily frequency and maximum energy of seismic waves increased obviously, the maximum of which were $121.1 \mathrm{~kJ}$ and 23 times, relatively, according with the characteristics of KDIS. The daily frequency and maximum energy returned to normal levels gradually with the workface \#10416 advancing further. A large number of microseismic events with greater magnitude mainly occurred on the side of the intake roadway (Figure 9), which verified the laws of the igneous sill breaking and energy releasing.

\section{Conclusions}

In this paper, the laws of energy accumulation, spreading, and attenuation for the THRS instability were studied theoretically, the sensitivity of those influencing factors was analyzed, and then the concept and criterion of KDIS were put forward. Afterwards, the KDIS in Yangliu Coal Mine, Huaibei Coalfield, China, was distinguished, in which results were verified by the numerical simulations and microseismic monitoring. The main conclusions are as follows:

(1) The total of the accumulated energy is composed of the bending elastic energy, the volumetric strain energy, and the kinetic energy generated by rock strata movement, which is positively correlated with the hanging length, overburden load, and kinematic velocity. The energy of seismic waves decreases gradually in the form of power with the increase of spreading distance, the residual of which is negatively correlated with the energy spreading distance and attenuation coefficient. The spread of seismic wave energy is greatly affected by the hanging length of rock strata and the spreading distance, relatively 
(2) One or more roof strata that play a leading role in inducing dynamic disasters of the underlying coal mass are defined as the KDIS. The greater the source energy, the shorter the spreading distance, and the smaller the attenuation coefficient are, the easier the roof strata are to become KDIS. The key stratum of ground control is not exactly equal to KDIS but may be the KDIS under certain conditions. The DIC is defined and used as the criterion of KDIS, based on which the THRS are divided into three types of KDIS, WDIS, and NDIS

(3) The disaster-inducing ability of the main THRS was analyzed and the igneous sill was judged as KDIS when the overlying coal seam \#10 was mined, taking the Yangliu Coal Mine as project background. By the methods of UDEC numerical simulation and microseismic monitoring, it was revealed that the igneous sill was broken and greater energy than that of common rock strata was released resulting to the occurrence of abnormal pressure when the workface of the coal seam \#10 was advanced 250 300 m, which verified the criterion of KDIS.

\section{Data Availability}

The data used to support the findings of this study are included within the article.

\section{Conflicts of Interest}

The authors declare that they have no conflicts of interest.

\section{Acknowledgments}

The work was supported by the National Natural Science Foundation of China (grant numbers 51974321, 51874314, and 51774292), Open Fund of Key Laboratory of Mining Disaster Prevention and Control (Grant No. MDPC202018), and Yueqi Young Scholar Project, China University of Mining \& Technology (Beijing).

\section{References}

[1] S. Kong, Y. Cheng, T. Ren, and H. Liu, "A sequential approach to control gas for the extraction of multi-gassy coal seams from traditional gas well drainage to mining-induced stress relief," Applied Energy, vol. 131, pp. 67-78, 2014.

[2] C. Xu, Q. Fu, K. Wang, C. Guo, and X. Li, "Effects of the deviatoric stress ratio on the coal failure and permeability during deep mining," Geotechnical and Geological Engineering, vol. 38, no. 6, pp. 6093-6105, 2020.

[3] Y. Xue, T. Teng, F. Dang, Z. Ma, S. Wang, and H. Xue, "Productivity analysis of fractured wells in reservoir of hydrogen and carbon based on dual-porosity medium model," International Journal of Hydrogen Energy, vol. 45, no. 39, pp. 20240-20249, 2020.

[4] L. Dou, T. Chen, S. Gong, H. He, and S. Zhang, "Rockburst hazard determination by using computed tomography technology in deep workface," Safety Science, vol. 50, no. 4, pp. 736-740, 2012.
[5] H. Guo, L. Yuan, B. Shen, Q. Qu, and J. Xue, "Mininginduced strata stress changes, fractures and gas flow dynamics in multi-seam Longwall mining," International Journal of Rock Mechanics and Mining Sciences, vol. 54, pp. 129139, 2012.

[6] P. Konicek, K. Soucek, L. Stas, and R. Singh, "Long-hole destress blasting for rockburst control during deep underground coal mining," International Journal of Rock Mechanics and Mining Sciences, vol. 61, pp. 141-153, 2013.

[7] C. Xu, G. Yang, K. Wang, and Q. Fu, "Uneven stress and permeability variation of mining-disturbed coal seam for targeted CBM drainage: a case study in Baode coal mine, Eastern Ordos Basin, China," Fuel, vol. 289, 2021.

[8] C. Zhang, L. Zhang, M. Li, and C. Wang, "A gas seepage modeling study for mitigating gas accumulation risk in upper protective coal seam mining process," Geofluids, vol. 2018, Article ID 8127207, 11 pages, 2018.

[9] C.-P. Lu, Y. Liu, H.-Y. Wang, and P.-F. Liu, "Microseismic signals of double-layer hard and thick igneous strata separation and fracturing," International Journal of Coal Geology, vol. 160-161, pp. 28-41, 2016.

[10] L. Dou, K. Yang, W. Liu, X. Chi, and Z. Wen, "Mining-induced stress-fissure field evolution and the disaster-causing mechanism in the high gas working face of the deep hard strata," Geofluids, vol. 2020, Article ID 8849666, 14 pages, 2020.

[11] G.-f. Wang, S.-y. Gong, Z.-1. Li, L.-m. Dou, W. Cai, and Y. Mao, "Evolution of stress concentration and energy release before rock bursts: two case studies from Xingan Coal Mine, Hegang, China," Rock Mechanics \& Rock Engineering, vol. 49, no. 8, pp. 3393-3401, 2016.

[12] L. Wang, Y.-p. Cheng, C. Xu, F.-h. An, K. Jin, and X.-l. Zhang, "The controlling effect of thick-hard igneous rock on pressure relief gas drainage and dynamic disasters in outburst coal seams," Natural Hazards, vol. 66, no. 2, pp. 1221-1241, 2013.

[13] C. Xu, Y. Cheng, T. Ren, L. Wang, S. Kong, and S. Lu, "Gas ejection accident analysis in bed splitting under igneous sills and the associated control technologies: a case study in the Yangliu Mine, Huaibei Coalfield, China," Natural Hazards, vol. 71, no. 1, pp. 109-134, 2014.

[14] C. Wu, J. Chu, S. Wu, and Y. Hong, "3D characterization of microbially induced carbonate precipitation in rock fracture and the resulted permeability reduction," Engineering Geology, vol. 249, pp. 23-30, 2019.

[15] M. Qian, X. Miao, and X. Jialin, "Theorical study of key stratum in ground control," Journal of China Coal Society, vol. 21, no. 3, pp. 225-230, 1996.

[16] B. Yu, "Behaviors of overlying strata in extra-thick coal seams using top-coal caving method," Journal of Rock Mechanics and Geotechnical Engineering, vol. 8, no. 2, pp. 238-247, 2016.

[17] Z. Zhu, Y. Wu, J. Han, and Y. Chen, “Overburden failure and ground pressure behaviour of Longwall top coal caving in hard multi-layered roof," Archives of Mining Sciences, vol. 64, no. 3, pp. 575-590, 2019.

[18] Y. Yong, T. Shihao, Z. Xiaogang, and L. Bo, "Dynamic effect and control of key strata break of immediate roof in fully mechanized mining with large mining height," Shock and Vibration, vol. 2015, Article ID 657818, 11 pages, 2015.

[19] J. Ju and J. Xu, "Structural characteristics of key strata and strata behaviour of a fully mechanized Longwall face with 7.0 $\mathrm{m}$ height chocks," International Journal of Rock Mechanics and Mining Sciences, vol. 58, pp. 46-54, 2013. 
[20] Z. Wen, E. Xing, S. Shi, and Y. Jiang, "Overlying strata structural modeling and support applicability analysis for large mining-height stopes," Journal of Loss Prevention in the Process Industries, vol. 57, pp. 94-100, 2019.

[21] B. Yu, R. Gao, T. Kuang, B. Huo, and X. Meng, "Engineering study on fracturing high-level hard rock strata by ground hydraulic action," Tunnelling and Underground Space Technology, vol. 86, pp. 156-164, 2019.

[22] B. Yu, J. Zhao, T. Kuang, and X. Meng, "In situ investigations into overburden failures of a super-thick coal seam for Longwall top coal caving," International Journal of Rock Mechanics and Mining Sciences, vol. 78, pp. 155-162, 2015.

[23] N. Li, E. Wang, M. Ge, and J. Liu, "The fracture mechanism and acoustic emission analysis of hard roof: a physical modeling study," Arabian Journal of Geosciences, vol. 8, no. 4, pp. 1895-1902, 2015.

[24] M. Zhang, H. Shimada, T. Sasaoka, K. Matsui, and L. Dou, "Evolution and effect of the stress concentration and rock failure in the deep multi-seam coal mining," Environmental Earth Sciences, vol. 72, no. 3, pp. 629-643, 2014.

[25] X.-y. Wang, W.-d. Wu, and B.-w. Wu, "Grouting of bed separation spaces to control sliding of the high-located main key stratum during Longwall mining," Quarterly Journal of Engineering Geology and Hydrogeology, vol. 53, no. 4, pp. 569578, 2020.

[26] C. Xu, Q. Fu, X. Cui, K. Wang, Y. Zhao, and Y. Cai, “Apparentdepth effects of the dynamic failure of thick hard rock strata on the underlying coal mass during underground mining," Rock Mechanics and Rock Engineering, vol. 52, no. 5, pp. 15651576, 2019.

[27] J. Jiang, P. Zhang, L. Nie, H. Li, L. Xu, and W. Wang, "Fracturing and dynamic response of high and thick strata of hard rocks," Chinese Journal of Rock Mechanics and Engineering, vol. 33, no. 7, pp. 1366-1372, 2014.

[28] C. Xu, L. Yuan, Y. Cheng, K. Wang, A. Zhou, and L. Shu, "Square-form structure failure model of mining-affected hard rock strata: theoretical derivation, application and verification," Environmental Earth Sciences, vol. 75, no. 16, p. 1180, 2016.

[29] Z. Mu, "Study of burst-energy principle of rock burst induced by roof stratum and its application," Journal of China University of Mining \& Technology, vol. 37, no. 6, pp. 149-150, 2008.

[30] H. He, L. Dou, A. Cao, and J. Fan, "Mechanisms of mining seismicity under large scale exploitation with multikey strata," Shock and Vibration, vol. 2015, Article ID 313069, 9 pages, 2015.

[31] J. He, L. Dou, S. Gong, J. Li, and Z. Ma, "Rock burst assessment and prediction by dynamic and static stress analysis based on micro-seismic monitoring," International Journal of Rock Mechanics and Mining Sciences, vol. 93, pp. 46-53, 2017.

[32] G. Cheng, L. Li, W. Zhu et al., "Microseismic investigation of mining-induced brittle fault activation in a Chinese coal mine," International Journal of Rock Mechanics and Mining Sciences, vol. 123, article 104096, 2019. 